\title{
Different Laboratory Abnormalities in COVID-19 Patients with Hypertension or Diabetes
}

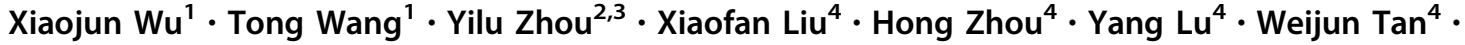 \\ Mingli Yuan ${ }^{4} \cdot$ Xuhong Ding ${ }^{1} \cdot$ Jinjing Zou ${ }^{1} \cdot$ Ruiyun $\mathrm{Li}^{1} \cdot \mathrm{Hailing} \mathrm{Liu}^{1} \cdot$ Rob M. Ewing ${ }^{2,3} \cdot \mathrm{Yi} \mathrm{Hu}^{4}$ (1) \\ Hanxiang $\mathrm{Nie}^{1}$ (D) Yihua Wang ${ }^{2,3,5}$
}

Received: 9 July 2020 / Accepted: 31 August 2020 / Published online: 30 September 2020

(c) Wuhan Institute of Virology, CAS 2020

\section{Dear Editor,}

The pandemic of COVID-19, a disease caused by severe acute respiratory syndrome coronavirus 2 (SARS-CoV-2; previously known as 2019-nCoV), has placed an enormous burden on health authorities in 213 countries and territories. At the time of writing, over 26 million cases have been recorded across the world, with more than $870 \mathrm{k}$ associated deaths (www.worldometers.info/coronavirus/). World Bank warns COVID-19 pandemic risks dramatic rise in poverty, with the majority of economies expecting to suffer from falling levels of GDP in 2020.

The main symptoms of COVID-19 are onset of a new continuous cough and/or a high temperature with symptoms ranging from mild to life threatening. Those who are

Xiaojun Wu, Tong Wang, Yilu Zhou, Xiaofan Liu, Hong Zhou have contributed equally to this work.

Yihua Wang

yihua.wang@soton.ac.uk

$\triangle$ Hanxiang Nie nhxbj@sohu.com

$\triangle \mathrm{Yi} \mathrm{Hu}$ huyi_pub@163.com

1 Department of Respiratory and Critical Medicine, Renmin Hospital of Wuhan University, Wuhan 430060, China

2 Biological Sciences, Faculty of Environmental and Life Sciences, University of Southampton,

Southampton SO17 1BJ, UK

3 Institute for Life Sciences, University of Southampton, Southampton SO17 1BJ, UK

4 Department of Pulmonary and Critical Care Medicine, The Central Hospital of Wuhan, Tongji Medical College, Huazhong University of Science and Technology, Wuhan 430014, China

5 NIHR Southampton Biomedical Research Centre, University Hospital Southampton, Southampton SO16 6YD, UK elderly or have pre-existing health issues are more likely to develop severe disease. The most prevalent comorbidity is hypertension, followed by diabetes (Guan et al. 2020a, b). We reported recently that hypertension is a risk factor for severe cases of COVID-19, independent of age and other variables (Liu et al. 2020a). An important question is why patients with hypertension and diabetes yield poorer clinical outcomes than those without. Human pathogenic coronavirus SARS-CoV-2 utilizes angiotensin-converting enzyme 2 (ACE2) as a receptor for viral cell entry. Since the levels of ACE2 are substantially increased in patients with hypertension or diabetes, who are treated with ACE inhibitors (ACEIs) and angiotensin II type-I receptor blockers (ARBs) (Ferrario et al. 2005), Fang and colleagues hypothesized that ACE2-stimulating drugs could potentially increase the risk of developing severe COVID-19 (Fang et al. 2020). This was not supported by a recent study led by Dr. Reynolds (Reynolds et al. 2020), whose analysis showed no positive association for ACEIs or ARBs for either the risk of SARS-CoV-2 infection or severe illness (Reynolds et al. 2020). What else might explain the poorer clinical outcomes of COVID-19 patients with hypertension or diabetes?

To explore this question, we re-analysed the same cohort of 99 COVID-19 patients discharged from the general wards of Renmin Hospital of Wuhan University between 5 February 2020 and 14 March 2020 (Ethics approval No: WDRY2020-K124) (Liu et al. 2020a, b). Demographic, clinical, laboratory and radiographic findings were extracted from electronic medical records. We asked whether there were any factors associated with COVID-19 patients with either hypertension or diabetes (summarised in Table 1). All data analyses and graphs were done in $R$ (V3.6.1) or GraphPad Prism (V8.2.1).

As expected, COVID-19 patients with health conditions like hypertension or diabetes had a longer length of hospital stay than those without, but this was at the limit of 
Table 1 Comparisons of demographic, clinical, laboratory and radiographic findings in COVID-19 patients with diabetes or hypertension.

\begin{tabular}{|c|c|c|c|c|}
\hline & \multicolumn{4}{|c|}{$P$ value, median (ICQ) } \\
\hline & \multicolumn{2}{|l|}{ Diabetes } & \multicolumn{2}{|l|}{ Hypertension } \\
\hline & $\begin{array}{l}- \\
(n=84)\end{array}$ & $\begin{array}{l}+ \\
(n=15)\end{array}$ & $\begin{array}{l}- \\
(n=65)\end{array}$ & $\begin{array}{l}+ \\
(n=34)\end{array}$ \\
\hline \multicolumn{5}{|l|}{ Demographics } \\
\hline Age & 0.2725 & & 0.0030 & \\
\hline Sex & 0.8578 & & 0.9846 & \\
\hline \multicolumn{5}{|l|}{ Signs and symptoms } \\
\hline Fever & 1.0000 & & 1.0000 & \\
\hline Cough & 0.1877 & & 0.2292 & \\
\hline Dyspnea & 1.0000 & & 0.7422 & \\
\hline Anorexia and/or lethargy & 1.0000 & & 0.4944 & \\
\hline Fatigue & 0.9510 & & 1.0000 & \\
\hline Myalgia and/or arthralgia & 1.0000 & & 0.6506 & \\
\hline Diarrhoea & 0.7846 & & 0.6871 & \\
\hline \multicolumn{5}{|l|}{ Laboratory findings } \\
\hline \multirow[t]{3}{*}{ White blood cell count $\left(\times 10^{9} / \mathrm{L}\right)$} & 0.8224 & & 0.0351 & \\
\hline & 4.87 & 4.11 & 4.47 & 5.50 \\
\hline & $(3.52-5.69)$ & $(3.23-6.12)$ & $(3.32-5.46)$ & $(3.94-6.65)$ \\
\hline \multirow[t]{3}{*}{ Neutrophil count $\left(\times 10^{9} / \mathrm{L}\right)$} & 0.6676 & & 0.0450 & \\
\hline & 2.93 & 3.25 & 2.81 & 3.62 \\
\hline & $(1.96-4.28)$ & $(2.21-4.67)$ & $(1.73-3.87)$ & $(2.54-5.12)$ \\
\hline \multirow[t]{3}{*}{ Lymphocyte count $\left(\times 10^{9} / \mathrm{L}\right)$} & 0.0192 & & 0.2595 & \\
\hline & 1.08 & 0.83 & 1.09 & 0.96 \\
\hline & $(0.80-1.45)$ & $(0.54-1.16)$ & $(0.77-1.45)$ & $(0.70-1.31)$ \\
\hline \multirow[t]{3}{*}{$D$-dimer $(\mu \mathrm{g} / \mathrm{L})$} & 0.0531 & & 0.0166 & \\
\hline & 0.38 & 0.56 & 0.36 & 0.66 \\
\hline & $(0.24-0.82)$ & $(0.44-1.11)$ & $(0.21-0.80)$ & $(0.41-0.93)$ \\
\hline \multirow[t]{3}{*}{ Lactate dehydrogenase (U/L) } & 0.1337 & & 0.0070 & \\
\hline & 191.0 & 215.0 & 180.0 & 222.5 \\
\hline & $(157.0-242.5)$ & $(195.0-258.0)$ & $(151.5-240.0)$ & $(192.5-263.2)$ \\
\hline \multirow[t]{3}{*}{ C-reactive protein $(\mathrm{mg} / \mathrm{dL})$} & 0.9086 & & 0.1421 & \\
\hline & 1.70 & 2.41 & 1.37 & 2.69 \\
\hline & $(0.52-4.07)$ & $(0.34-4.78)$ & $(0.51-3.24)$ & $(0.53-5.84)$ \\
\hline \multicolumn{5}{|l|}{ Radiographic findings } \\
\hline \multirow[t]{3}{*}{ HRCT peak score } & 0.0119 & & 0.0088 & \\
\hline & 14.5 & 21.0 & 14.0 & 19.0 \\
\hline & $(8.0-20.3)$ & $(15.5-30.0)$ & $(8.0-20.0)$ & $(14.0-25.8)$ \\
\hline
\end{tabular}

Data are $P$ values. Medians and IQR (interquartile range) are also provided for laboratory and radiographic findings. $P$ values were calculated by Mann-Whitney $U$ test or Chi squared test as appropriate using R (V3.6.1) or GraphPad Prism (V8.2.1). Numbers in bold mean $P$ values less than 0.05 and are statistically significant. statistical significance (Fig. 1A, $P=0.07$ ). To check the extent of pulmonary pathology in COVID-19 patients, we developed a high-resolution computed tomography (HRCT) score system considering both radiographic features and distributions (Liu et al. 2020b; Yuan et al. 2020). In brief, the HRCT findings were graded on a 3-point scale: normal attenuation (1 point), ground-glass attenuation (2 points), and consolidation ( 3 points). Each lung zone (6 lung zones in total for each patient) was assigned a following scale according to the distribution of the affected lung parenchyma: normal ( 0 point), $<25 \%$ abnormality (1 point), $25 \%-50 \%$ abnormality (2 points), $50 \%-75 \%$ abnormality ( 3 points), and $>75 \%$ abnormality (4 points). The 4-point scale of the lung parenchyma distribution and 

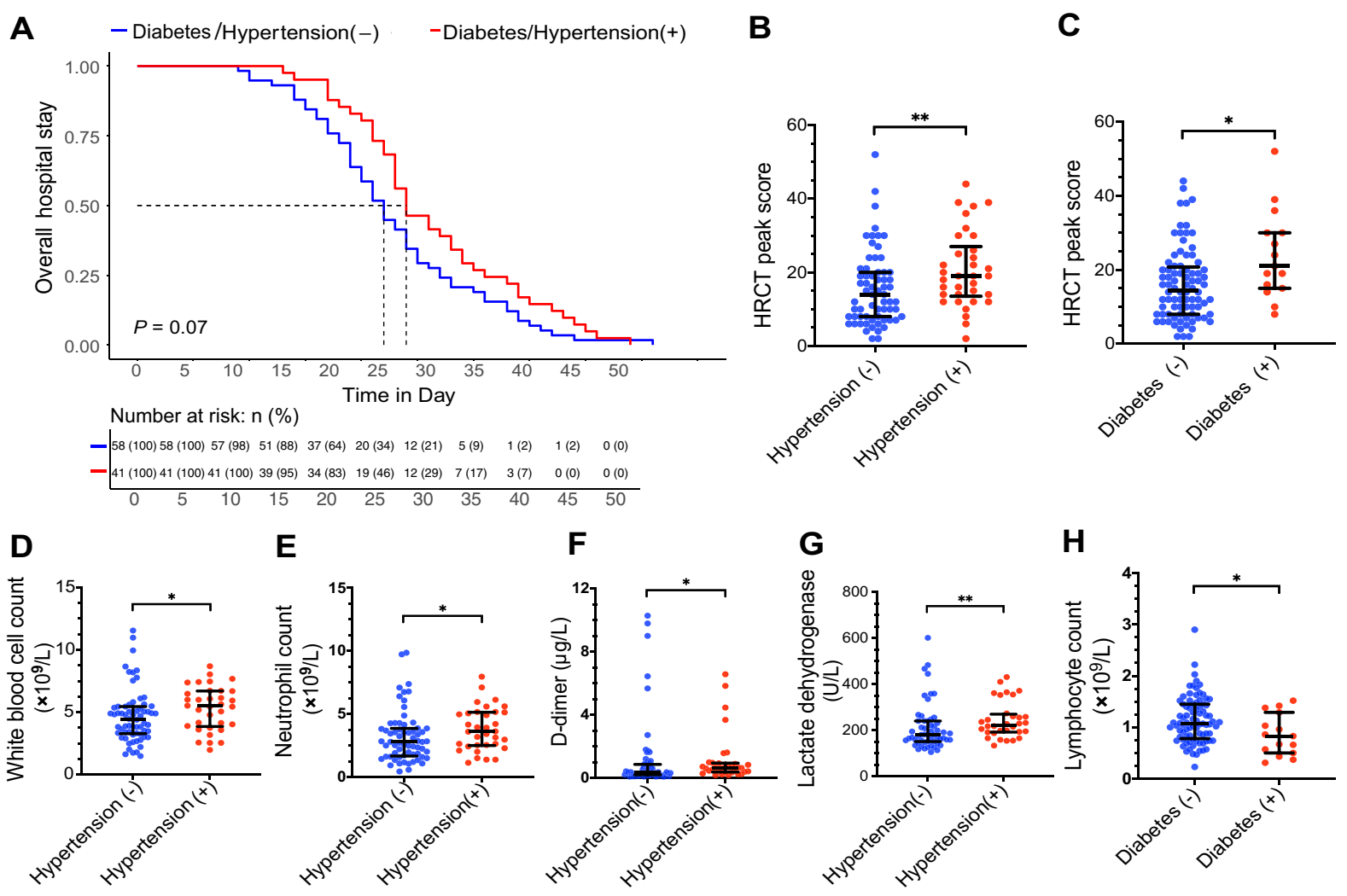

Fig. 1 Impacts of hypertension or diabetes on length of hospital stay, HRCT peak scores and laboratory findings in COVID-19 patients. A Kaplan-Meier plot showing the overall hospital stay in COVID-19 patients with hypertension or diabetes and those without. Patients are separated into two groups. The control group is those patients, who are free of diabetes and hypertension $(n=58)$, and the other group is those with either diabetes or hypertension $(n=41)$. Numbers below are $\mathrm{n}(\%) . P$ value was calculated by log-rank test. B Graph showing the distributions of HRCT peak scores in COVID-19 patients with or

the radiographic scale described above were then multiplied to produce a weighted score for each zone. Points from all zones were then summed for a final total cumulative score (HRCT score), with values ranging from 0 to 72. HRCT peak scores are the highest HRCT score during disease course, which reflex maximal chest HRCT abnormalities. We found HRCT peak scores for hypertensive COVID-19 patients were higher compared to non-hypertensive ones (median: 19.0; IQR: 14.0-25.8vs. median: 14; IQR: 8.0-20.0) $(P=0.0088)$ (Table 1; Fig. 1B). HRCT peak scores in COVID-19 patients with diabetes (median: 21.0; IQR, interquartile range: 15.5-30.0) were also higher compared to those without (median: 14.5; IQR: 8.0-20.3) $(P=0.0119)$ (Table 1; Fig. 1C). These findings confirmed an increased disease severity in COVID-19 patients with hypertension or diabetes (Liu et al. 2020a).

Most interestingly, in laboratory findings on admission (Table 1), we found white blood cell counts (Fig. 1D; median: 5.50 vs. $4.47 ; P=0.035$ ), neutrophil counts without hypertension. C Graph showing the distributions of HRCT peak scores in COVID-19 patients with or without diabetes. DG Graphs showing white blood cell counts (D), neutrophil counts (E), D-dimer $(\mathbf{F})$ and lactate dehydrogenase (G) in COVID-19 patients with or without hypertension. H Graph showing lymphocyte counts in COVID-19 patients with or without diabetes. Data in $(\mathbf{B}-\mathbf{H})$ are median and IQR. $* P<0.05$. ${ }^{* *} P<0.01 . P$ values in $(\mathbf{B}-\mathbf{H})$ were calculated by Mann-Whitney $U$ test.

(Fig. 1E; median: 3.62 vs. 2.81; $P=0.045$ ), D-dimer (Fig. 1F; median: 0.66 vs. 0.36; $P=0.017$ ) and lactate dehydrogenase (LDH) (Fig. 1G; median: 222.5 vs. 180.0; $P=0.007)$ were all increased in hypertensive COVID-19 patients compared to non-hypertensive ones; while lymphocyte count was not significantly changed in hypertensive COVID-19 patients (median: 0.96 vs. 1.09; $P=0.260$ ). In contrast, there was a significant decrease in lymphocyte count in COVID-19 patients with diabetes compared with those without (Fig. $1 \mathrm{H}$; median: $1.08 \mathrm{vs}$. $0.83 ; P=0.019)$; while changes in white blood cell counts, neutrophil counts, D-dimer and LDH were not significant $(P>0.05)$ in COVID-19 patients with diabetes. In addition, hypertensive COVID-19 patients were older than nonhypertensive ones $(P=0.003)$, but this was not the case for diabetic COVID-19 patients $(P=0.273)$. There were no significant differences in C-reactive protein, sex and common symptoms (such as fever, cough, dyspnoea, 
fatigue, anorexia and/or lethargy, myalgia and/or arthralgia and diarrhoea) for both hypertension and diabetes.

SARS-CoV-2 infections lead to a fast activation of innate immune cells, especially in COVID-19 patients developing severe disease (Zou et al. 2020). It was reported that circulating neutrophil numbers are consistently higher in survivors of COVID-19 than in non-survivors, and the infection also induces lymphopenia (low level of lymphocytes in the blood) (Zhou et al. 2020). In our analysis, we found on admission hypertensive COVID-19 patients had higher neutrophil numbers compared to non-hypertensive ones, while lymphopenia was more frequently observed in COVID-19 patients with diabetes. These results suggest different mechanisms exist for hypertension or diabetes as risk factors for severe cases of COVID-19. It is known that both hypertensive and diabetes patients have impaired immune response to infections (Lopez Gelston and Mitchell 2017; Zhu et al. 2020). Low-grade inflammation is known to facilitate the development of hypertension, and poor glycaemic control influences cytokine profile and $\mathrm{T}$ cell activation, which were reflected by the laboratory findings in this study. However, more lab work is required to confirm these in COVID-19. Established mouse models of hypertension and diabetes can be applied to the K18hACE2 transgenic mice for this purpose.

There are several limitations in this study. (1) Interpretation of our findings might be limited by the sample size. (2) This study is limited by its retrospective nature, the non-standardised documentation resulting in the inability to remove the influence of age on laboratory findings. Despite these limitations, we were able to identify different laboratory abnormalities on admission in COVID-19 patients with hypertension or diabetes, which might shed light on future mechanistic studies.

Acknowledgements We acknowledge all the patients involved in this study, and appreciate all the frontline medical and nursing staff involved in the diagnosis and treatment of patients in Wuhan. This project was jointly funded by Medical Research Council (UK) [MR/ S025480/1] and a Key Project of Science and Technology on COVID-19 of Hubei Province [No. 2020FCA002]. YZ was supported by an Institute for Life Sciences (University of Southampton) $\mathrm{PhD}$ Studentship.

\section{Compliance with ethical standards}

Conflict of interest The authors declare that they have no conflict of interest.

Animal and Human Rights Statement All methods were carried out in accordance with relevant guidelines and regulations. This retrospective study was approved by the Ethics Committee of Renmin Hospital of Wuhan University, Hubei, China (No. WDRY2020-K124), and the requirement for informed consent was waived by the Ethics Committee due to a public health outbreak investigation.

\section{References}

Fang L, Karakiulakis G, Roth M (2020) Are patients with hypertension and diabetes mellitus at increased risk for covid-19 infection? Lancet Respir Med 8:e21

Ferrario CM, Jessup J, Chappell MC, Averill DB, Brosnihan KB, Tallant EA, Diz DI, Gallagher PE (2005) Effect of angiotensinconverting enzyme inhibition and angiotensin ii receptor blockers on cardiac angiotensin-converting enzyme 2. Circulation 111:2605-2610

Guan WJ, Liang WH, Zhao Y, Liang HR, Chen ZS, Li YM, Liu XQ, Chen RC, Tang CL, Wang T, Ou CQ, Li L, Chen PY, Sang L, Wang W, Li JF, Li CC, Ou LM, Cheng B, Xiong S, Ni ZY, Xiang J, Hu Y, Liu L, Shan H, Lei CL, Peng YX, Wei L, Liu Y, Hu YH, Peng P, Wang JM, Liu JY, Chen Z, Li G, Zheng ZJ, Qiu SQ, Luo J, Ye CJ, Zhu SY, Cheng LL, Ye F, Li SY, Zheng JP, Zhang NF, Zhong NS, He JX, China Medical Treatment Expert Group for C (2020a) Comorbidity and its impact on 1590 patients with covid-19 in China: a nationwide analysis. Eur Respir J 55:2000547

Guan WJ, Ni ZY, Hu Y, Liang WH, Ou CQ, He JX, Liu L, Shan H, Lei CL, Hui DSC, Du B, Li LJ, Zeng G, Yuen KY, Chen RC, Tang CL, Wang T, Chen PY, Xiang J, Li SY, Wang JL, Liang ZJ, Peng YX, Wei L, Liu Y, Hu YH, Peng P, Wang JM, Liu JY, Chen Z, Li G, Zheng ZJ, Qiu SQ, Luo J, Ye CJ, Zhu SY, Zhong NS, China Medical Treatment Expert Group for C (2020b) Clinical characteristics of coronavirus disease 2019 in China. N Engl J Med 382:1708-1720

Liu X, Zhou H, Zhou Y, Wu X, Zhao Y, Lu Y, Tan W, Yuan M, Ding X, Zou J, Li R, Liu H, Ewing RM, Hu Y, Nie H, Wang Y (2020a) Risk factors associated with disease severity and length of hospital stay in covid-19 patients. J Infect 81:e95-e97

Liu X, Zhou H, Zhou Y, Wu X, Zhao Y, Lu Y, Tan W, Yuan M, Ding $\mathrm{X}$, Zou J, Li R, Liu H, Ewing RM, Hu Y, Nie H, Wang Y (2020b) Temporal radiographic changes in covid-19 patients: relationship to disease severity and viral clearance. Sci Rep 10:10263

Lopez Gelston CA, Mitchell BM (2017) Recent advances in immunity and hypertension. Am J Hypertens 30:643-652

Reynolds HR, Adhikari S, Pulgarin C, Troxel AB, Iturrate E, Johnson SB, Hausvater A, Newman JD, Berger JS, Bangalore S, Katz SD, Fishman GI, Kunichoff D, Chen Y, Ogedegbe G, Hochman JS (2020) Renin-angiotensin-aldosterone system inhibitors and risk of covid-19. N Engl J Med 382:2441-2448

Yuan M, Yin W, Tao Z, Tan W, Hu Y (2020) Association of radiologic findings with mortality of patients infected with 2019 novel coronavirus in wuhan, China. PLoS ONE 15:e0230548

Zhou F, Yu T, Du R, Fan G, Liu Y, Liu Z, Xiang J, Wang Y, Song B, Gu X, Guan L, Wei Y, Li H, Wu X, Xu J, Tu S, Zhang Y, Chen H, Cao B (2020) Clinical course and risk factors for mortality of adult inpatients with covid-19 in wuhan, China: a retrospective cohort study. Lancet 395:1054-1062

Zhu L, She ZG, Cheng X, Qin JJ, Zhang XJ, Cai J, Lei F, Wang H, Xie J, Wang W, Li H, Zhang P, Song X, Chen X, Xiang M, Zhang C, Bai L, Xiang D, Chen MM, Liu Y, Yan Y, Liu M, Mao W, Zou J, Liu L, Chen G, Luo P, Xiao B, Zhang C, Zhang Z, Lu Z, Wang J, Lu H, Xia X, Wang D, Liao X, Peng G, Ye P, Yang J, Yuan Y, Huang X, Guo J, Zhang BH, Li H (2020) Association of blood glucose control and outcomes in patients with covid-19 and pre-existing type 2 diabetes. Cell Metab 395:1054-1062

Zou L, Ruan F, Huang M, Liang L, Huang H, Hong Z, Yu J, Kang M, Song Y, Xia J, Guo Q, Song T, He J, Yen HL, Peiris M, Wu J (2020) Sars-cov-2 viral load in upper respiratory specimens of infected patients. N Engl J Med 382:1177-1179 